\title{
Comparative Study for Adsorption of Acidic and Basic Dyes on Activated Carbon Prepared From Date Stone by Different Activation Agent
}

\author{
Azhaar Radhi Jabbar ${ }^{a^{*}}$, Abbas Kalaf Mohammad ${ }^{a}$ \\ ${ }^{a}$ Faculty of Engineering - University of Al-Qadisiyah-Iraq.
}

\section{A R T ICLE INFO}

Article history:

Received 26 November 2019

Received in revised form 02 January 2020

Accepted 23 January 2020

\section{Keywords:}

Date stone

Chemical activation

Adsorption

Acidic and basic dyes

\begin{abstract}
A B S T R A C T
This research includes a lab scale work to investigate the feasibility of treating waste water which is polluted with dyes exhausted from textile factory by using the adsorption process. Three types of activated carbon were prepared using locally available waste material (date stone). Chemical activation method with (zinc chloride, potassium hydroxide, or phosphoric acid) is used to prepare carbon. Firstly, the materials were carbonized at $275^{\circ} \mathrm{C}$ for $90 \mathrm{~min}$, and then the carbonized materials were treated with (4 molar) solution of acid, base, or salt for 24 hours. Finally, these materials were activated at $600^{\circ} \mathrm{C}$ for two hours in the presence of nitrogen gas flow. The resulted activated carbons were checked by its (BET) surface area analysis and surface morphology by SEM. The surface area values were $(815,950,600) \mathrm{m}^{2} / \mathrm{g}$ for carbon produced from the activation of date stone by phosphoric acid, potassium hydroxide, or zinc chloride respectively. SEM characterizations show that activated carbons that prepared from potassium hydroxide have higher surface area and good adsorption characteristics than that prepared from activation with phosphoric acid or zinc chloride. The adsorption process was carried out using two types of dyes. The first one is acidic (methyl orange) and the other is basic (bismark brown). The adsorption isotherms and kinetics were investigated for both dyes at temperatures $(30,40,50,60)^{\circ} \mathrm{C}$ for concentration range equal to (6-16) $\mathrm{mg} / \mathrm{l}$. The adsorption data of equilibrium were presented by using two common adsorption isotherm equations. The data was fitted fairly well with Langmuir isotherm for both dyes on all types of prepared activated carbons. The kinetics of adsorption was studied by using two kinetic equations, pseudo first order and pseudo second order. The results showed a rapid increase in the rate of adsorption at the initial until equilibrium achieved. The pseudo second order model represented the data very well with confidence level 0.99 .
\end{abstract}

\section{Introduction}

Environmental pollution control has been a concerning issue in many countries, especially air and water pollution [1]. Waste effluent from the textile industry can be problematic due to the presence of dyes in the final effluent. Removal of dyes from textile effluents that is toxic and very dangerous for human beings is a major problem, because of the difficulty of treating these dyes by conventional waste water treatment methods such as coagulation, chemical oxidation, membrane filtration ,solvent extraction ,chemical precipitation ,osmosis ,....etc. These methods have not been very successful since dye is stable to light, oxidizing agent, high capital cost and operational cost or secondary sludge disposal problems.

All of these problems made the scientists look for cheaper and more effective means and reach to the adsorption technology on activated carbon

* Corresponding author.

E-mail address: azhaarazhaar17@gmail.com (Azhaar Jabbar) https://doi.org/10.30772/qjes.v13i1.622 2411-7773/@ 2020 University of Al-Qadisiyah. All rights reserved. 


\begin{tabular}{|llll}
\hline $\begin{array}{l}\text { Nomenclature } \\
\text { BET }\end{array}$ & Brunauer-Emmett-Teller (surface area) & Q1: & $\begin{array}{l}\text { The Langmuir maximum uptake of Methyl orange and Bismark } \\
\text { brown per unit mass of adsorbent (mg/g) }\end{array}$ \\
$\mathrm{C}_{0}$ & Initial concentration of dye $\mathrm{mg} / \mathrm{L}$ & & \\
$\mathrm{C}_{1}$ & The concentration of the stock solution & $\mathrm{Qe}$ & Absorbance amount (mg/g) \\
$\mathrm{C}_{2}$ & The second concentration after dilution & $\mathrm{V}$ & Solution volume $\mathrm{L}$ \\
$\mathrm{Ce}$ & Equilibrium concentration $\mathrm{mg} / \mathrm{L}$ & $\mathrm{V}_{1}$ & Volume from the stock solution. \\
$\mathrm{Kf}:$ & The adsorption or distribution coefficient & $\mathrm{V}_{2}$ & Volume of the distilled water required for dilution \\
$\mathrm{N}:$ & Indication of the favourableness of the adsorption process & $\mathrm{W}$ & Weight of the adsorbent \\
\hline
\end{tabular}

[2]. Activated carbon is widely used on an industrial scale as an adsorbent mainly in the purification /separation of liquids and gases and also as a catalyst and catalyst support [3]. Activated carbon is a carbonaceous material with a highly porous structure and large internal surface area. It can be prepared from the processing of lignocellulosic raw materials under high temperatures. Any cheap material with a high carbon content and low in organics can be used as a raw material for the production of activated carbon. literature review indicates that there were many attempts to obtain low cost activated carbon from agricultural wastes such as wood [4], peat [5], nutshells [6], [7], or rice husk [8].

In this work, date stone is investigated as an alternative low-cost precursor to prepare activated carbon using $\mathrm{KOH}, \mathrm{H}_{3} \mathrm{PO}_{4}$, and $\mathrm{ZnCL}_{2}$ as activation agent for the removal of methyl orange (acid dye) and bismark brown (basic dye) from aqueous solutions. The study also includes equilibrium adsorption isotherms and kinetics, which could provide useful information and insight in the further operation and design fields.

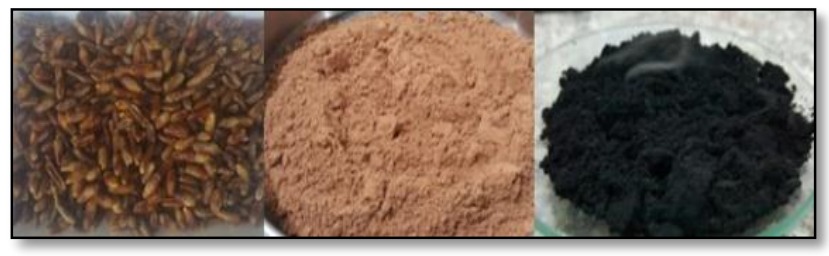

Figure 1. photographic image for raw date powder before and after activation

\section{Experimental work}

\subsection{Materials}

Nitrogen (supplied from Al-Diwaniyah North factory, Iraq) of purity greater than $95 \%$ is used as an inert gas medium during the activation process. Phosphoric acid (Aldrich, Germany), Zinc chloride (Aldrich, Germany), and potassium hydroxide (Alpha chemika, India) with purity greater than $99 \%$ are used as chemical reagents. Aqueous stock solutions of methyl orange and bismark brown were prepared by dissolving methyl orange $\left(\mathrm{C}_{14} \mathrm{H}_{14} \mathrm{~N}_{3} \mathrm{NaO}_{3} \mathrm{~S}\right.$, MW: $327 \mathrm{gm} / \mathrm{mol}$, Sigma-Aldrich) and bismark brown $\left(\mathrm{C}_{11} \mathrm{H}_{10} \mathrm{~N}_{8}\right.$, MW: $419 \mathrm{gm} / \mathrm{mol}$, Sigma-Aldrich) in distilled water.

\subsection{Preparation of date stone activated carbon}

Date stone waste is collected from local farms at Al-Diwaniyah city, south of Iraq. It was washed thoroughly with distilled water then it was dried for thirty days under direct sunlight to ensure vaporization of all water and volatile materials. Next, one kilogram of previously dried waste material (date stone) was grinded using an electrical grinder (JIQI, Generic Co., china) for about 30 minutes. The produced powder was screened for 600 micrometers using a screening analysis apparatus (Gilson Company).
A schematic diagram illustrating the experimental setup of the activated carbon preparation system is shown in Fig. 2 and 3. The reactor was made from a piece of 6-inch carbon steel pipe with $15 \mathrm{~cm}$ length. The two ends of the pipe piece were enclosed by two 7 inch carbon steel plates. The bottom end was welded while the upper end was fitted using two screws to enable us of changing raw materials inside the reactor. The reactor was put inside an electric furnace (Hysc Co., model: mf-12, China) equipped with input and output points. The nitrogen gas from the cylinders was passed through a pressure regulator and falling ball manometer equipped with suitable value to control the measurement of the pressure and flow rate of nitrogen gas. Then, the $\mathrm{N}_{2}$ gas flows through (1/4) inch stainless steel pipe which was partly coiled around the reactor to ensure adequate preheating of the gas before entering the reactor. The effluent $\mathrm{N}_{2}$ gas pipe from the top of the reactor was connected with a thermocouple and temperature recorder.

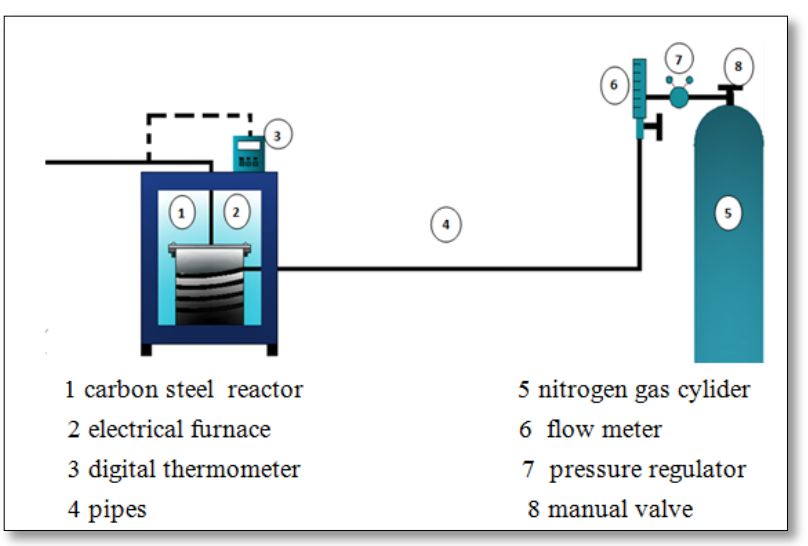

Figure 2. A schematic diagram for the activation system

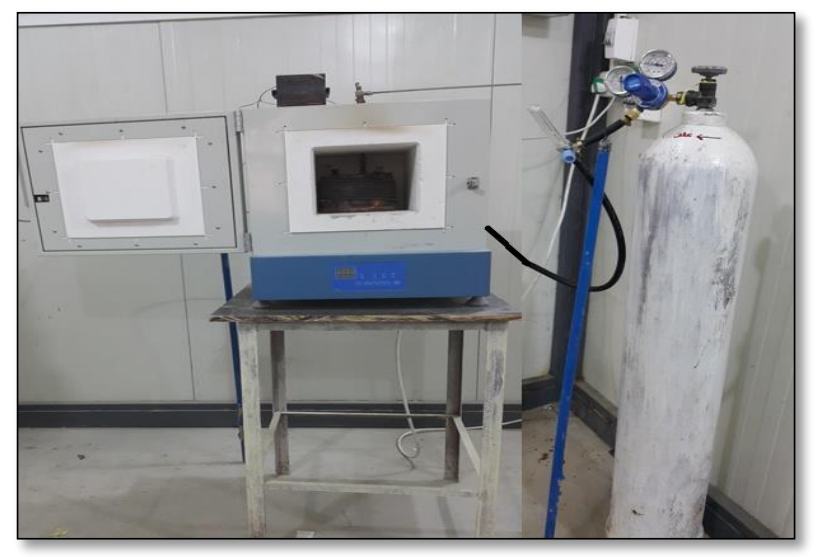

Figure 3. photographic image of activation system 
(40 gm) of date stone powder was put in a graphite crucible and covered with mineral wool in order to prevent the powdered material from being conveyed with $\mathrm{N} 2$ gas during burning. Then, the crucible was put inside the reactor which is positioned in the furnace. The nitrogen gas was allowed to flow at a rate of $(4 \mathrm{~L} / \mathrm{min})$. The sample was pre-carbonized by setting the temperature of the furnace at $275 \mathrm{o} \mathrm{C}$ for $90 \mathrm{~min}$. The resulted char was allowed to cool at room temperature, then it was soaked with (4M) solution of phosphoric acid, potassium hydroxide, or zinc chloride for $24 \mathrm{hrs}$. Then the sample was filtrated using vacuum filtration apparatus and dried for 2 hours at room temperature. The filtrate was put in the graphite crucible inside the reactor for activation. The temperature of the reactor was set at $6000 \mathrm{C}$ and the nitrogen gas flow rate at $4 \mathrm{~L} / \mathrm{min}$ for two hours. The produced activated carbon was allowed to cool at room temperature under nitrogen. Then, it was washed with distilled water several times until the rinsed water $\mathrm{pH}$ equal to 6 and finally it was dried at $105 \mathrm{C}$ for 6 hours in a hot air oven. After that the prepared activated carbon samples were analyzed via SEM, surface area for morphology.

\subsection{Adsorption}

The dyes solutions were prepared by dissolving $(0.05) \mathrm{gm}$ of each dye in 1 liter distilled water. In order to prepare standard solutions with defined concentrations, the previously prepared solutions were diluted with a suitable volume of distilled water according to the law of dilution. Five solutions of standard concentrations for each dye were prepared for the processing, and used them to determine the characteristics of adsorption isotherms and kinetics.

$$
\mathrm{C}_{1} * \mathrm{~V}_{1}=\mathrm{C}_{2} * \mathrm{~V}_{2}
$$

Equilibrium information, usually known as adsorption isotherms, explains how the adsorbate responds with adsorbents, and show an overall description of the nature of the interaction. It is important to optimize the design of an adsorption system [9]. The parameters gained from the various models supply valuable data on the surface characteristic of the adsorbent and its affinity for the adsorbate. Langmuire and Freundlich isotherm equations have been used for such analysis in this work. The adsorption isotherms for methyl orange and bismark brown on the different kinds of prepared activated carbons were examined at $(30,40,50$ and 60$){ }^{\circ} \mathrm{C}$ where (10) $\mathrm{ml}$ of dye solution at specified concentration was mixed with (0.05) gm of activated carbon in a graduated test tube. Then, the tube was put in a constant temperature water bath.

Firstly, the equilibrium time was estimated by taking samples from each test tube at different time duration. The equilibrium time is defined here as the time at which negligible concentration change is noticed within a one-half hour period.

Secondly, the adsorption equilibrium isotherms were examined by mixing different concentrations of dyes solutions $(6,8,10,12,14,16) \mathrm{ppm}$ with $0.05 \mathrm{gm}$ of each kind of prepared activated carbons. The mixture is allowed to reach equilibrium time in a constant temperature water bath. At the end of the process, samples were taken for analysis. Amount of dyes that were adsorbed can be measured from the following law:

$$
q e=\frac{(C 0-C e) \cdot V}{W}
$$

Finally, the adsorption kinetics were investigated in a procedure similar to that of equilibrium but the samples were taken at different times until the final sample was taken at equilibrium attending.

\section{Results and discussion}

\subsection{Characterization of activated carbon}

The improvement of surface properties for activated carbon means improvement of adsorption efficiency since adsorption process is a surface phenomena, therefore surface morphology measurements are carried out on the prepared activated carbon samples using Scanning Electron Microscopy (SEM, FEI Co., Model: Inspect S50, Netherlands), BET surface area (ASAP2020, Micromeritics, USA).

\subsubsection{Effect or raw material}

Raw material properties and characteristics have a major importance since its content of violet matter and fibers determines the quantity of produced activated carbon. Fig. 4 shows the SEM morphology for date powder waste raw material. The SEM graph confirms the formation of micro-pore on the raw materials, but with significant differences in the pore size, shape and diameter.

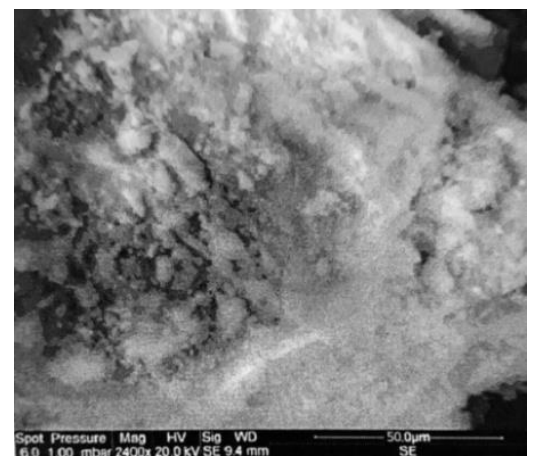

Figure 4. SEM image of date stone powder

\subsubsection{Effect of carbonization process}

Tars and low vapour pressure materials vaporize and cellulose matters burn out through carbonization process due to high temperature treatment, so the surface area of carboneous structure is available for adsorption of adsorbable solutes.

Fig. 5 illustrates an SEM picture for date stone after the carbonization process. It is clearly shown that the carbonization treatment makes the raw material more amorphous and porous but with different extents. Carbonized date stone has more porous structure with a random arrangement of different sizes of a pore. Also, it could be recognized that carbonized material have conglomerates of carboneous matter that could be transmitted to more porous by activation by chemical agents.

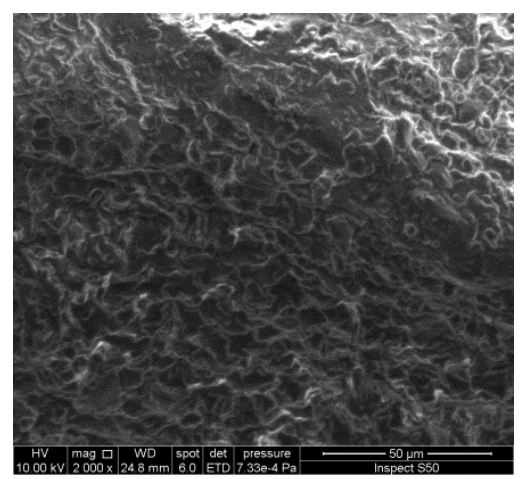

Figure 5. SEM image for carbonized date stone 


\subsubsection{Effect of activation process}

Opening of enclosed pores and decreasing of conglomerates of carboneous materials are noticed through activation process due to very high temperature treatment and the effect of various chemical activation agents.

Figs. 6 to 8 show SEM pictures for date stone after activation process via phosphoric acid, zinc chloride, and potassium hydroxide, respectively. It is clearly shown that the activation treatment makes the carbonized waste materials well developed and very porous but with identified differences due to differences in raw materials and activation agents.

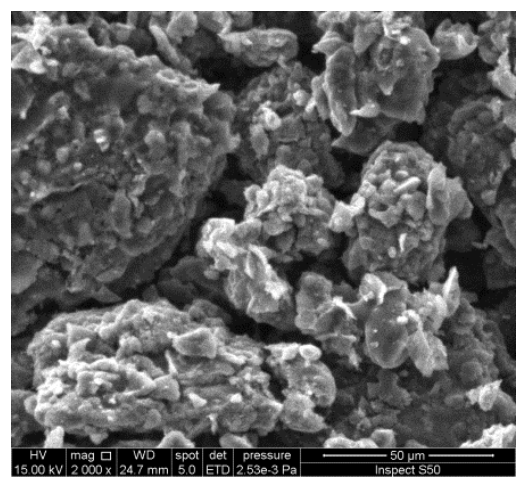

Figure 6. SEM image of activated carbon prepared from date stone by phosphoric acid activation agent

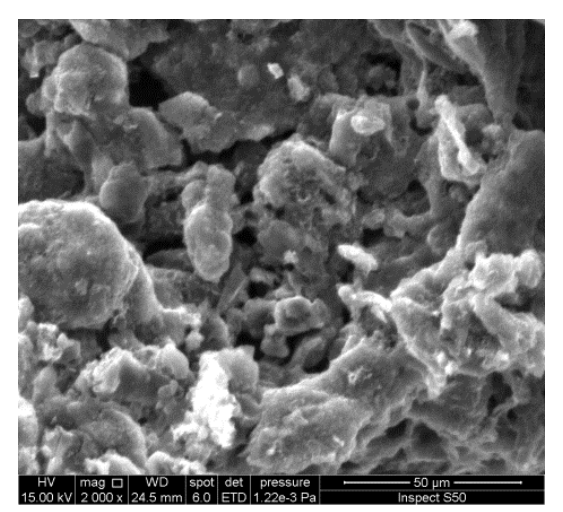

Figure 7. SEM image of activated carbon prepared from date stone by potassium hydroxide activation agent

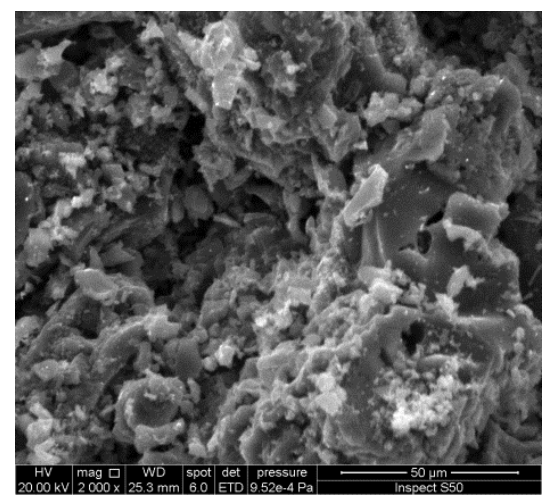

Figure 8: SEM image of activated carbon prepared from date stone by zinc chloride activation agent
The figures indicate that the activated carbons that prepared from date stone waste material have heterogeneous rough surface of random arrangement of cracks and cavities with low porosity. Also, it could be noted from these figures that potassium hydroxide activation agents yield activated carbon with a high density of different size pores but with less uniformity of arrangement. Furthermore, potassium hydroxide has the lowest impact on the environment than phosphoric acid and zinc chloride activation agents. This result agrees with the researcher [10]and [11].

This difference in the pore prise the activated carbon made from date stone with potassium hydroxide good adsorption characteristic compare with that from date stone with other activators for both acid and basic dyes. Table 1 shows some properties for the prepared activated carbon.

Table 1. BET surface area of activated carbon

\begin{tabular}{lll}
\hline Activated carbon & Surface area $\mathbf{~ m}^{2} / \mathbf{g}$ & Pore type \\
\hline date $+\mathrm{H}_{3} \mathrm{PO}_{4}$ & 815 & Micro-pore \\
date $+\mathrm{KOH}$ & 950 & Micro-pore \\
date $+\mathrm{ZnCL}_{2}$ & 600 & Micro-pore \\
\hline
\end{tabular}

\subsection{Equilibrium of adsorption}

The adsorption equilibrium isotherms give an understanding of suitability of adsorbent for a special application, and show how the amount adsorbed depends upon the equilibrium concentration of the fluid at constant temperature. The dyes concentrations and temperatures values were chosen in viewing to the expected waste water condition in the textile factory exhaust.

Figs. 9 to 14 show the adsorption equilibrium isotherms for adsorption of bismark brown and methyl orange at different temperatures on activated carbons prepared from date stone employing phosphoric acid, potassium hydroxide and zinc chloride as activator, respectively. These figures indicate that all curves for any specified dye (either acidic or basic) on all types of prepared activated carbons are same in nature and are of the classical adsorption isotherm type1 shape. The experimental results were fitted with the most well known adsorption isotherms that describe the adsorption of solutes from aqueous solution on to activated carbons. These isotherms called Langmuir and Freundlich equations.

The Langmuir adsorption isotherm represents adsorbate-adsorbent systems in which the range of the adsorbate coverage is excluded to one molecular layer [12]. In another words, Langmuir model is used for homogeneous surfaces, while Freundlich model is considered to be suitable for highly heterogeneous surfaces [12].

Table 2 shows the average values of confidence level $\left(\mathrm{R}^{2}\right)$ for Langmuir and Freundlichisotherm models for adsorption of methyl orange and bismark brown dyes on different types of prepared activated carbon. The comparison confidence level values for the two isotherm models give indication that Langmuir isotherm fits the data fairly well than Freundlich model. In addition, this indication could be better seen by plotting the experimental data using Langmuir and Freundlich adsorption isotherms in linear forms according to equation (3) and (4), respectively.

$$
\begin{aligned}
& \text { Langmuir } \frac{c e}{q e}=\frac{1}{a l k l}+\frac{1}{q l} c e \\
& \text { Freundlich } \\
& \log q e=\log k f+\frac{1}{n} \log c e
\end{aligned}
$$

The data were plotted according to equations (3) and (4) as shown in Figs. 15-26. These figures clearly show that the Langmuir adsorption 
isotherm represent the experimental work fairly well and better than Freundlich adsorption isotherm. The conclusion was that the adsorption of basic and acidic dyes on all types of activated carbon is limited to a single monolayer and all types of prepared activated carbons have homogeneous surfaces. but with different levels of homogeneity.

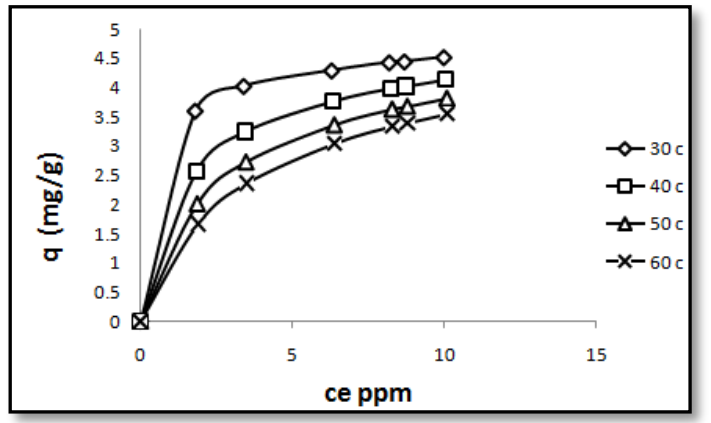

Figure 9. Adsorption equilibrium isotherms for bismark brown adsorbed on activated carbon prepared from date stone using phosphoric acid as activator

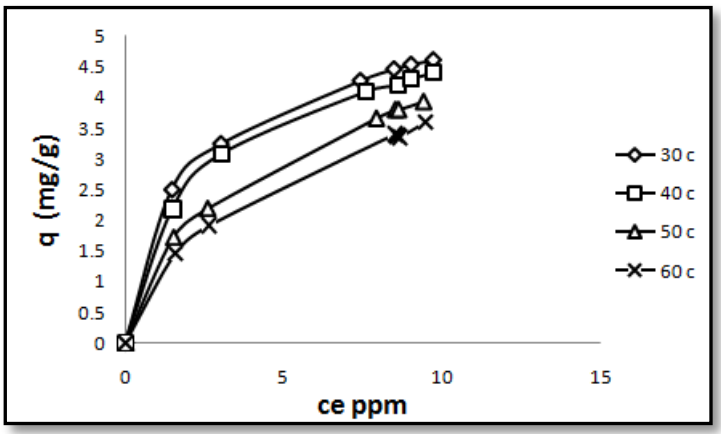

Figure 10. Adsorption equilibrium isotherms for bismark brown adsorbed on activated carbon prepared from date stone using potassuim hydroxide as activator

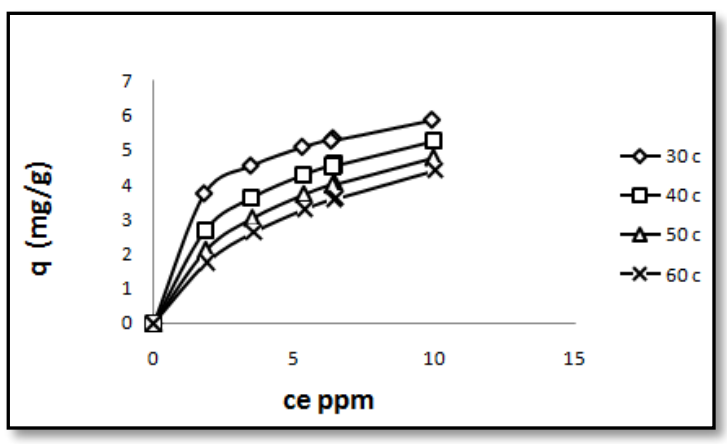

Figure 11. Adsorption equilibrium isotherms for bismark brown adsorbed on activated carbon prepared from date stone using zinc chloride as activator

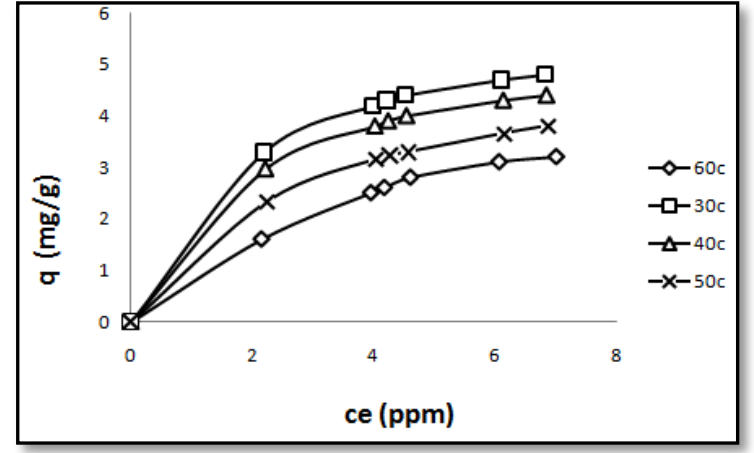

Figure 12. Adsorption equilibrium isotherms for methyl orange adsorbed on activated carbon prepared from date stone using phosphoric acid as activator

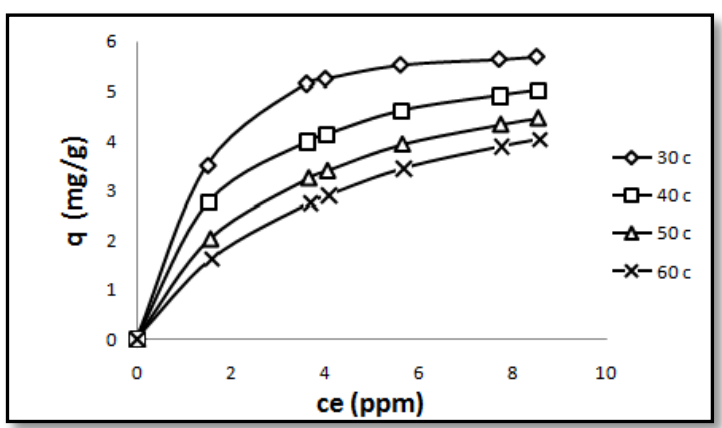

Figure 13. Adsorption equilibrium isotherms for methyl orange adsorbed on activated carbon prepared from date stone using potassium hydroxide as activator

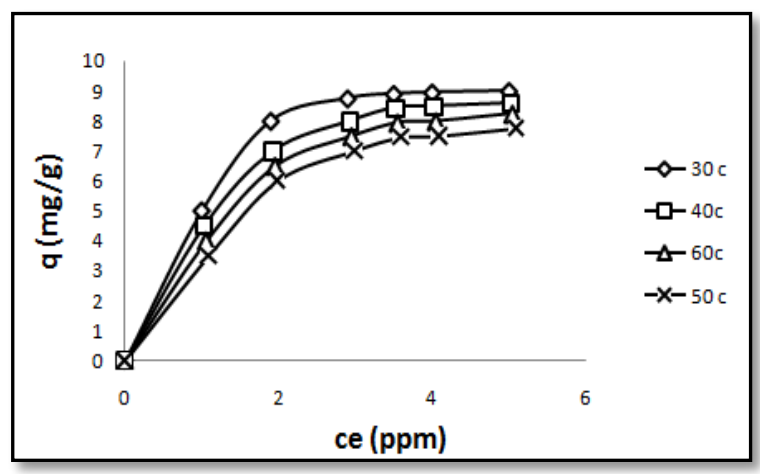

Figure 14. Adsorption equilibrium isotherms for methyl orange adsorbed on activated carbon prepared from date stone using zinc chloride as activator 


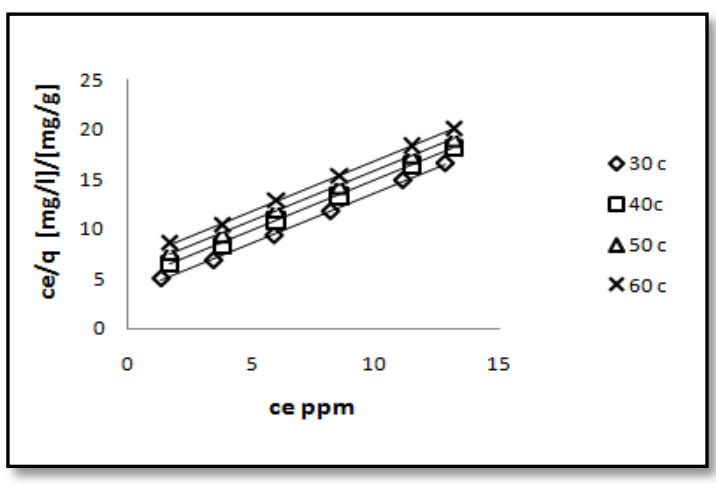

Figure 15. Langmuir adsorption isotherm for bismark brown on activated carbon prepared from date stone with phosphoric acid at different temperature

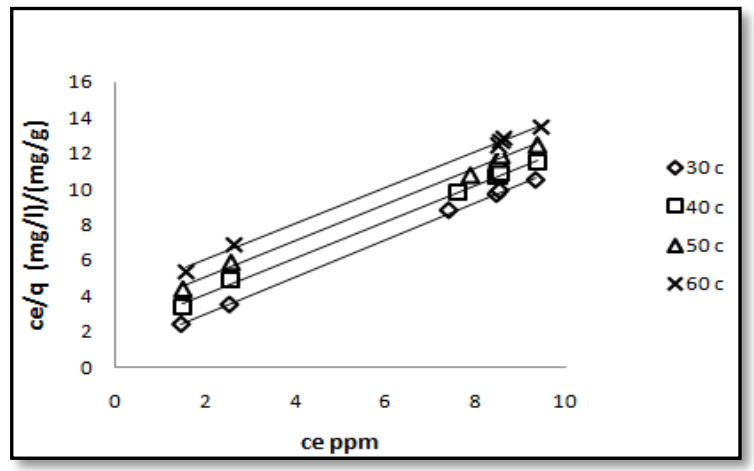

Figure 16. Langmuir adsorption isotherm for bismark brown on activated carbon prepared from date stone with potassium hydroxide at different temperature

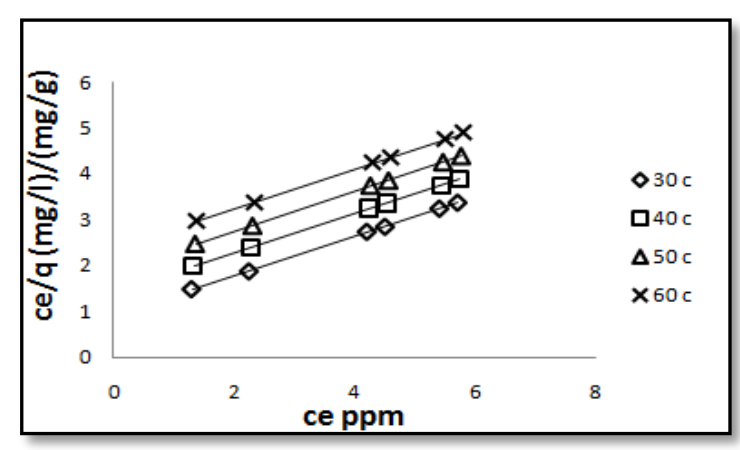

Figure 17. Langmuir adsorption isotherm for bismark brown on activated carbon prepared from date stone with zinc chloride at different temperature

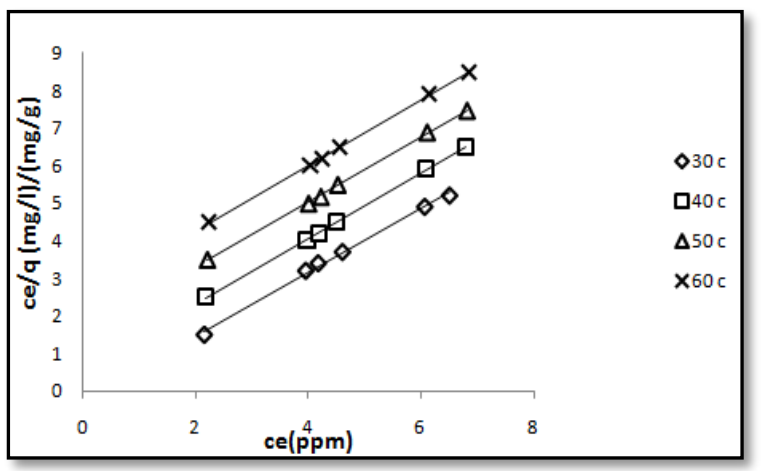

Figure 18. Langmuir adsorption isotherm for methyl orange on activated carbon prepared from date stone with phosphoric acid at different temperature

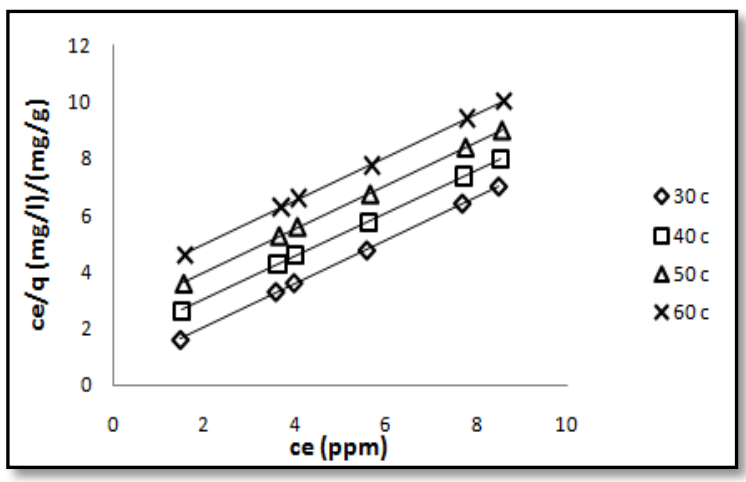

Figure 19. Langmuir adsorption isotherm for methyl orange on activated carbon prepared from date stone with potassium hydroxide at different temperature

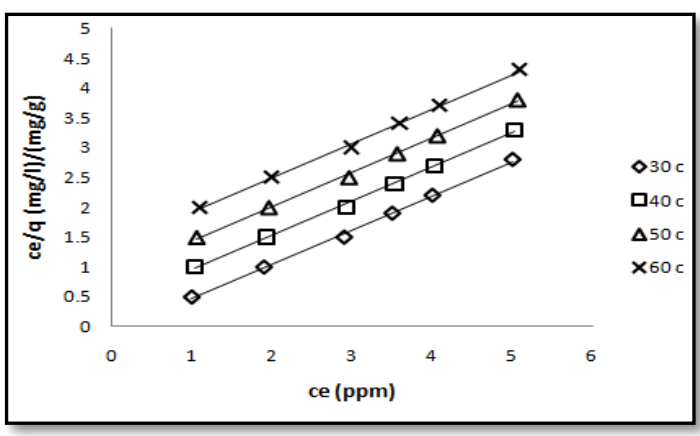

Figure 20. Langmuir adsorption isotherm for methyl orange on activated carbon prepared from date stone with zinc chloride at different temperature 
Table 2. Average confidence interval levels (R2) values for Langmuir and Freundlich models

\begin{tabular}{llllll}
\hline \multirow{2}{*}{$\begin{array}{l}\text { Raw } \\
\text { material agents }\end{array}$} & \multicolumn{4}{c}{$\begin{array}{c}\text { Adsorbate type } \\
\text { Mctivated }\end{array}$} & \multicolumn{3}{c}{ Bismark brown } & \multicolumn{2}{c}{ Methyl orange } \\
\cline { 3 - 6 } & $\mathbf{R}^{\mathbf{2}}$ & $\mathbf{R}^{\mathbf{2}}$ & $\mathbf{R}^{\mathbf{2}}$ & $\mathbf{R}^{\mathbf{2}}$ \\
& $\begin{array}{l}\text { Langmuir } \\
\text { model }\end{array}$ & $\begin{array}{l}\text { Freundlich } \\
\text { model }\end{array}$ & $\begin{array}{l}\text { Langmuir } \\
\text { model }\end{array}$ & $\begin{array}{l}\text { Freundlich } \\
\text { model }\end{array}$ \\
\hline date & $\mathrm{H}_{3} \mathrm{PO}_{4}$ & 0.994 & 0.68 & 0.996 & 0.92 \\
date & $\mathrm{KOH}_{\text {date }}$ & 0.998 & 0.76 & 0.996 & 0.85 \\
$\mathrm{ZnCL}$ & 0.993 & 0.84 & 0.998 & 0.62 \\
\hline
\end{tabular}

\section{Kinetic of adsorption}

The rates of adsorption of bimark brown and methyl orange on to different types of prepared activated carbons were presented in Figs. 21 to 26 at $(30,40,50 \text { or } 60)^{\circ} \mathrm{C}$. These figures show the rapid increase of capacity for the two dyes during the first two hours and then the low increase of capacity until equilibrium attending. The fast rate of adsorption at the initial stages may be due to the availability of the unoccupied active sites on the adsorbent and the high concentration of adsorbable solute molecules.

The experimental kinetic data of bismark brown and methyl orange on activated carbons prepared from date stone and activated using phosphoric acid, potassium hydroxide or zinc chloride were correlated by two kinetics models: pseudo-first order and pseudo-second order. Equations (5) and (6) represent of the two kinetics model

$$
\text { Langmuir } \quad \frac{c e}{q e}=\frac{1}{a l k l}+\frac{1}{q l} c e
$$

Freundlich $\quad \log q e=\log k f+\frac{1}{n} \log c e$

The results show that pseudo-second order adsorption kinetic model correlates the experimental data very well. Therefore, the best fit was achieved with this model equation. Furthermore, the experimental data were presented in linear form by applying equations (4) and (5) of pseudo first order and pseudo-second order kinetics model equations and shown in Figs. 27 to 30. Also, the figures indicate that the second order kinetic model correlate the data fairly well. This interpreting that multiple stages were included in the adsorption process. In addition, the results explain that the adsorption of bismark brown and methyl orange dyes onto activated carbons involve more than one process .

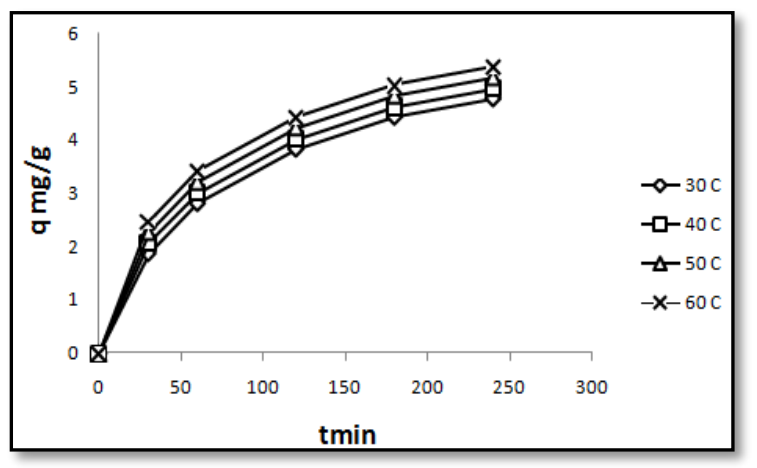

Figure 21. Rate of adsorption of bismark brown on activated carbon prepared from date stone and activated by phosphoric acid

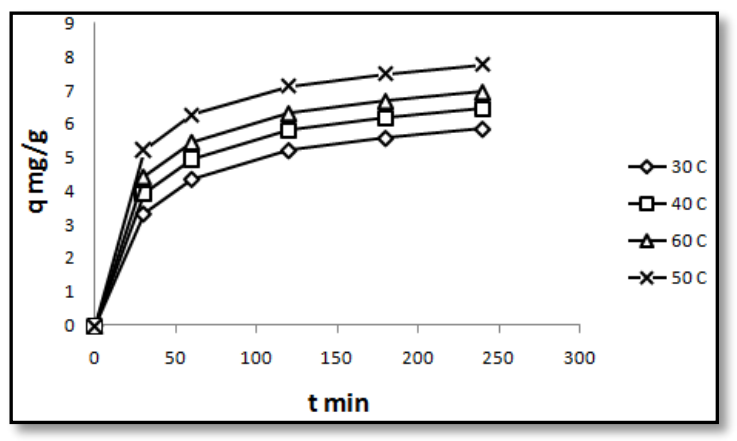

Figure 22. Rate of adsorption of bismark brown on activated carbon prepared from date stone and activated by potassium hydroxide

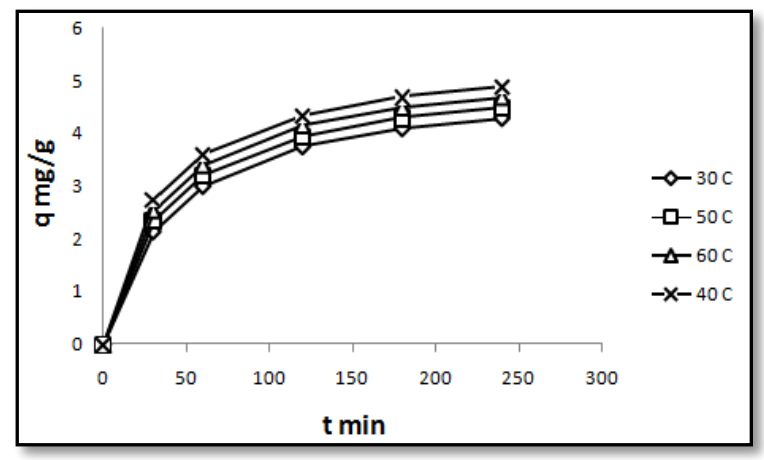

Figure 23. Rate of adsorption of bismark brown on activated carbon prepared from date stone and activated by zinc chloride

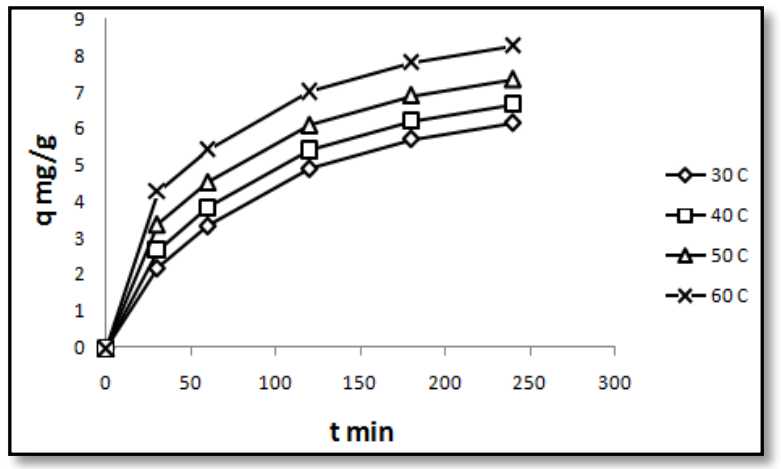

Figure 24. Rate of adsorption of methyl orange on activated carbon prepared from date stone and activated by phosphoric acid

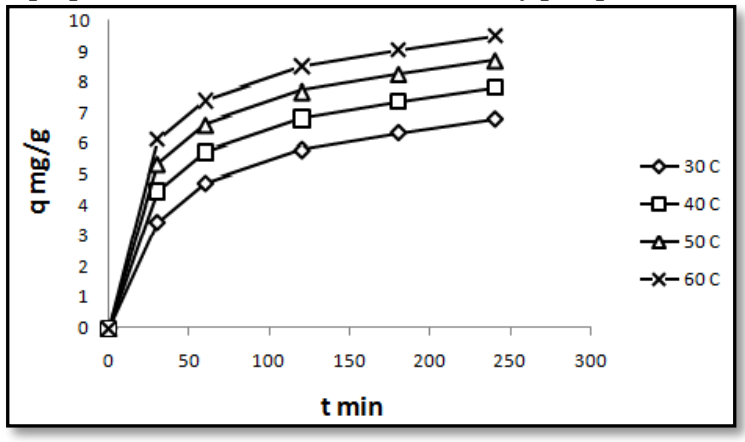

Figure 25. Rate of adsorption of methyl orange on activated carbon prepared from date stone and activated by potassium hydroxide 


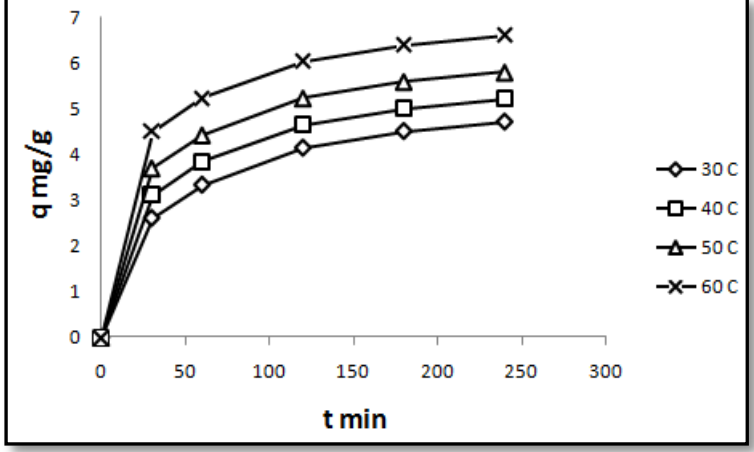

Figure 26. Rate of adsorption of methyl orange on activated carbon prepared from date stone and activated by zinc chloride

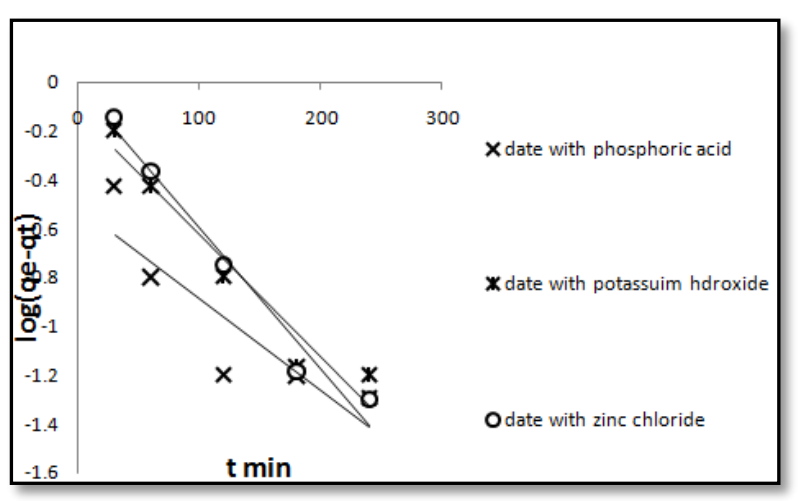

Figure 27. First order kinetic model for the adsorption of bismark brown dye onto different types of prepared activated carbons at $30^{\circ} \mathrm{C}$

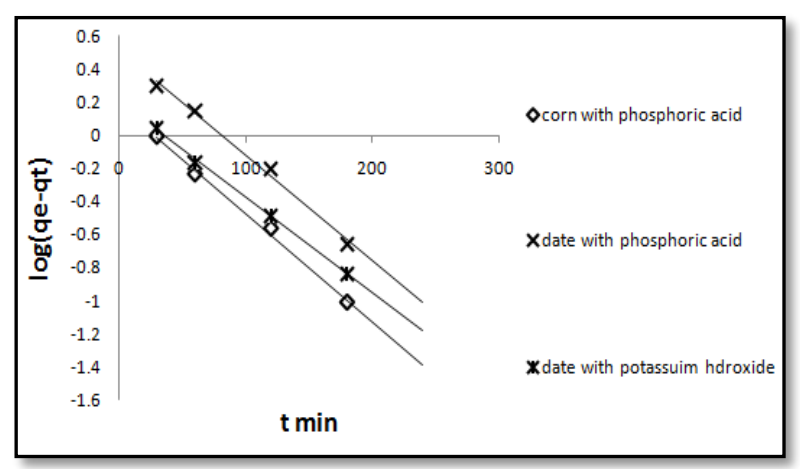

Figure 28. first order kinetic model for the adsorption of methyl orange dye onto different types of prepared activated carbons at $30^{\circ} \mathrm{C}$

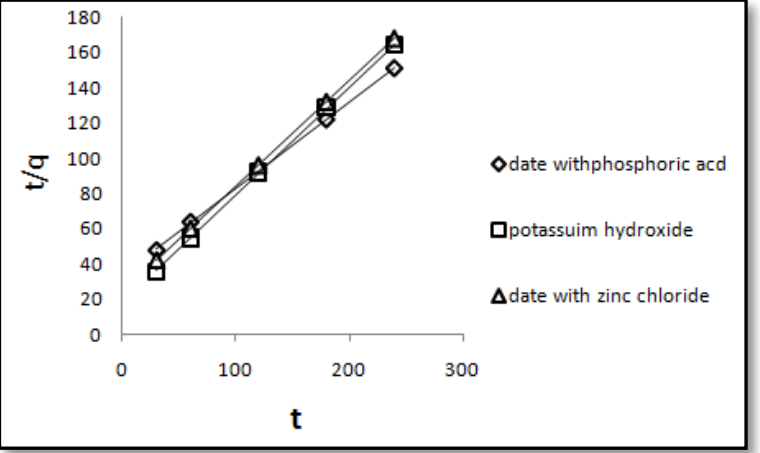

Figure 29. second order kinetic model for the adsorption of bismark brown dye onto different types of prepared activated carbons at $30^{\circ} \mathrm{C}$

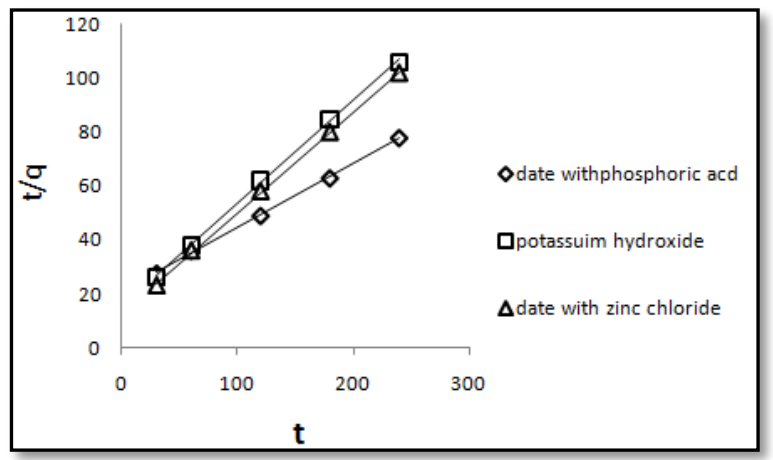

Figure 30. Second order kinetic model for the adsorption of methyl orange dye onto different types of prepared activated carbons at $30^{\circ} \mathrm{C}$

Table 3. Average value for Freundlich isotherm parameters for bismark brown at different temperature $(30,40,50,60){ }^{\circ} \mathrm{C}$

\begin{tabular}{lllll}
\hline $\begin{array}{l}\text { Dye } \\
\text { type }\end{array}$ & $\begin{array}{l}\text { Raw } \\
\text { material }\end{array}$ & $\begin{array}{l}\text { Activated } \\
\text { agent }\end{array}$ & Kf =intercept & $\begin{array}{l}\mathbf{1} / \mathbf{n} \\
\text { =slope }\end{array}$ \\
\hline \multirow{3}{*}{ Methyl } & Date & $\mathrm{H}_{3} \mathrm{PO}_{4}$ & 1.258 & 0.255 \\
orange & Date & $\mathrm{KOH}$ & 1.411 & 0.372 \\
& Date & $\mathrm{ZnCL}_{2}$ & 1.065 & 0.472 \\
Bismark & Date & $\mathrm{H}_{3} \mathrm{PO}_{4}$ & 1.466 & 0.306 \\
brown & Date & $\mathrm{KOH}$ & 1.593 & 0.363 \\
\hline
\end{tabular}

Table 4. The average value for Langmuir isotherm parameters for methyl orange at different temperature $(30,40,50,60){ }^{\circ} \mathrm{C}$

\begin{tabular}{lllll}
\hline Dye type & $\begin{array}{l}\text { Raw } \\
\text { material }\end{array}$ & $\begin{array}{l}\text { Activated } \\
\text { agent }\end{array}$ & ql & al \\
\hline \multirow{3}{*}{ Methyl } & Date & $\mathrm{H}_{3} \mathrm{PO}_{4}$ & 1.743 & 1.492 \\
orange & Date & $\mathrm{KOH}$ & 0.956 & 0.741 \\
& Date & $\mathrm{ZnCL}_{2}$ & 1.613 & 2.68 \\
Bismark & Date & $\mathrm{H}_{3} \mathrm{PO}_{4}$ & 0.901 & 0.912 \\
brown & Date & $\mathrm{KOH}$ & 0.546 & 0.562 \\
& Date & $\mathrm{ZnCL}_{2}$ & 0.503 & 0.385 \\
\hline
\end{tabular}




\section{Conclusion}

The present study shows that the AC can be used as a potential adsorbent for the removal of both bismark brown and methyl orange from their aqueous solutions. The following conclusions can be drawn from the present work:

1. Porous activated carbon could be prepared from date stone, the results showed that date stone activated with phosphoric acid, potassium hydroxide, or zinc chloride gives activated carbon with a good adsorption capacity highly porous structure and surface area with different shape and size.

2. The optimum condition to obtain high surface area and porosity depends on the agents used in the activation and the temperature Hence, activation with high temperature resulted in lower surface area than lower temperature, therefore the suitable temperature for activation was $600^{\circ} \mathrm{C}$ in this work and potassium hydroxide gives activated carbon with good adsorption characteristic than that activated with phosphoric acid or zinc chloride.

3. The acidic dyes (methyl orange) show higher adsorption capacity than basic dye (bismark brown).

4. The adsorption isotherm data were fitted well by Langmuir isotherm, for bismark brown and Methyl orange, respectively, while the kinetics data were well represented by the pseudo-second-order kinetic model.

5. The results showed that the strength of adsorption for bismark brown is higher than methyl orange on most types of prepared activated carbons. Hence, Methyl orange was adsorbed with a higher amount than bismark brown, because methyl orange needs less energy for adsorption on activated carbon than bismark brown.

\section{REFERENCES}

[1] O. Gulnaz, A. Kaya, F. Matyar, B. Arikan, Sorption of basic dyes from aqueous solution by activated sludge, Journal of Hazardous Materials, 108(3) (2004) 183-188.
[2] V.K. Gupta, D. Mohan, S. Sharma, M. Sharma, Removal of basic dyes (rhodamine B and methylene blue) from aqueous solutions using bagasse fly ash, Separation Science and Technology, 35(13) (2000) 2097-2113.

[3] S. Yakout, G.S. El-Deen, Characterization of activated carbon prepared by phosphoric acid activation of olive stones, Arabian Journal of Chemistry, 9 (2016) S1155-S1162.

[4] S. Bashkova, T.J. Bandosz, The effects of urea modification and heat treatment on the process of NO2 removal by wood-based activated carbon, Journal of colloid and interface science, 333(1) (2009) 97-103.

[5] L.A. Sepulveda, C.C. Santana, Effect of solution temperature, $\mathrm{pH}$ and ionic strength on dye adsorption onto Magellanic peat, Environmental technology, 34(8) (2013) 967-977.

[6] F. Rodriguez-Reinoso, The role of carbon materials in heterogeneous catalysis, Carbon, 36(3) (1998) 159-175.

[7] K. Jurewicz, R. Pietrzak, P. Nowicki, H. Wachowska, Capacitance behaviour of brown coal based active carbon modified through chemical reaction with urea, Electrochimica Acta, 53(16) (2008) 5469-5475.

[8] A. Ganesan, R. Mukherjee, J. Raj, M.M. Shaijumon, Nanoporous rice husk derived carbon for gas storage and high performance electrochemical energy storage, Journal of Porous Materials, 21(5) (2014) 839-847.

[9] B. Royer, N.F. Cardoso, E.C. Lima, J.C. Vaghetti, N.M. Simon, T. Calvete, R.C. Veses, Applications of Brazilian pine-fruit shell in natural and carbonized forms as adsorbents to removal of methylene blue from aqueous solutions-Kinetic and equilibrium study, Journal of Hazardous Materials, 164(2-3) (2009) 1213-1222.

[10] F. Bouhamed, Z. Elouear, J. Bouzid, Adsorptive removal of copper (II) from aqueous solutions on activated carbon prepared from Tunisian date stones: equilibrium, kinetics and thermodynamics, Journal of the Taiwan Institute of Chemical Engineers, 43(5) (2012) 741-749.

[11] V. Njoku, B. Hameed, Preparation and characterization of activated carbon from corncob by chemical activation with $\mathrm{H} 3 \mathrm{PO} 4$ for 2, 4dichlorophenoxyacetic acid adsorption, Chemical Engineering Journal, 173(2) (2011) 391-399.

[12] S. Timur, I.C. Kantarli, E. Ikizoglu, J. Yanik, Preparation of activated carbons from Oreganum stalks by chemical activation, Energy \& Fuels, 20(6) (2006) 2636-2641. 